\title{
O campo da educação e demandas para a terapia ocupacional no Brasil**
}

\section{The field of education: possible contributions of occupational therapy in Brazil}

\author{
Roseli Esquerdo Lopes ${ }^{1}$ e Carla Regina Silva ${ }^{2}$
}

\begin{abstract}
LOPES, R. E.; SILVA, C. R. O campo da educação e demandas para a terapia ocupacional no Brasil. Rev. Ter. Ocup. Univ. São Paulo, v.18, n. 3, p. 158-164, set./dez. 2007.

RESUMO: Trata-se de discutir a necessidade de intervenções sociais calcadas na educação e na defesa dos direitos decorrentes da cidadania, para adolescentes e jovens vulneráveis socialmente, tomando-se o caso da escola pública no Brasil. O Projeto METUIA tem trabalhado na construção de bases teóricas para a elaboração de programas terapêutico-ocupacionais na área social, bem como na sua experimentação prática. A partir de experiências e estudos desenvolvidos pelo Núcleo UFSCar do Projeto METUIA, com relação à violência na e da escola pública, especialmente a de ensino médio, defende-se a ampliação da atuação da terapia ocupacional no campo da educação incorporando questões pertinentes à maioria dos estudantes brasileiros no ciclo básico. Parte-se do pressuposto que a terapia ocupacional espelha o que seus profissionais pensam e produzem e a forma como se posicionam politicamente frente às questões sociais que a eles se colocam. Seus métodos estão condicionados a determinadas problemáticas que são percebidas e incorporadas como de sua responsabilidade e para as quais se articulam possíveis soluções. A desigualdade, a pobreza são problemáticas relevantes no bojo da questão social brasileira, adquirindo configurações que requerem uma revisão imediata das profissões e das pertinências do papel profissional.
\end{abstract}

PALAVRAS-CHAVE: Terapia Ocupacional Social. Educação. Escola Pública. Adolescência e Juventude.

\footnotetext{
* Parte deste trabalho foi apresentada no X Congresso Brasileiro de Terapia OCupaCional, realizado em Goiânia/GO, 2007, por uma das autoras que coordenou a mesa "A Terapia Ocupacional e as Ações na Educação: aprofundando interfaces", que compôs o evento.

1. Terapeuta Ocupacional pela Universidade de São Paulo (USP), Especialista em Saúde Pública pela USP, Mestre em Educação pela Universidade Federal de São Carlos (UFSCar) e Doutora em Educação pela Universidade Estadual de Campinas. Professora Associada do Departamento de Terapia Ocupacional e do Programa de Pós-Graduação em Educação da UFSCar. Coordenadora do Grupo de Pesquisa Terapia Ocupacional e Educação no Campo Social - CNPq e do Núcleo UFSCar do Projeto METUIA.

2. Terapeuta Ocupacional e Mestre em Educação pela UFSCar. Integrante do Grupo de Pesquisa Terapia Ocupacional e Educação no Campo Social - CNPq e Terapeuta Ocupacional do Núcleo UFSCar do Projeto METUIA.

Endereço para correspondência: Laboratório METUIA do Departamento de Terapia Ocupacional da UFSCar. Via Washington Luis, km 235 - São Carlos, SP. CEP: 13565-905.relopes@ufscar.br e carla.metuia@gmail.com
} 
O terapeuta ocupacional, como articulador social, demanda a constituição de um campo de conhecimento teórico e prático que implica na possibilidade de compreender, articular e produzir reflexões com relação a três domínios: o macro-estrutural e conceitual, o político-operacional e o da atenção pessoal e coletiva. Tais planos se interpenetram no cotidiano, compondo a dinâmica da realidade profissional à qual a terapia ocupacional social se filia: uma prática assentada na intersetorialidade e fundada na transdisciplinaridade (GALHEIGO, 1999).

Dentre uma infinidade de questões permeadas pelas implicações macro-estruturais e pelas demandas sociais, a terapia ocupacional social problematiza o valor empregado às ações do sujeito e, portanto, ao próprio sujeito, cujos desdobramentos resultam numa divisão de papéis, de lugares que lhe cabem ou não na sociedade contemporânea, e nos quais sua condição de classe é essencial. Estas problemáticas, parametrizadas pela compreensão sócio-histórica, nos permitem afirmar que, na sociedade capitalista, de consumo e do individualismo exacerbado, temos uma estrutura cada vez mais refinada de dominação, vigilância e privação.

Sendo assim, é coerente que a terapia ocupacional social se debruce sobre questões acerca das necessidades de grupos sociais que estão expostos diretamente à precarização do trabalho, à vulnerabilidade relacional e, conseqüentemente, aos processos de ruptura das redes sociais de suporte ${ }^{(1)}$.

As transformações sociais, em particular no mundo do trabalho, que geraram a degradação das relações de trabalho e dos sistemas de proteção associados, produziram sujeitos considerados "inválidos conjunturais" (DONZELOT, 1986) ou "sobrantes" (CASTEL, 1997) que estão marginalizados em relação às oportunidades de suas própria sobrevivência, quer seja no que refere ao trabalho ou à moradia, educação, cultura, saúde.

É, então, de extrema importância buscar novos nexos capazes de dar conta desta terapia ocupacional que vem se constituindo no campo social. Os estudos sociológicos, antropológicos, educacionais e políticos têm sido incluídos nas práticas e reflexões, do mesmo modo que se revela a necessidade de concepções transdisciplinares e de ações intersetoriais.

Em busca da defesa da cidadania, no cotidiano das práticas e na luta pela efetiva conquista dos direitos de grupos populares, a intervenção da terapia ocupacional social tem como estratégias: - a ação mediadora na relação estabelecida com o Outro, por intermédio do técnico, das atividades ou de ambos; - a intervenção com e no território ${ }^{(2)}$; - a busca da universalização de direitos de cidadania e da produção de formas de criação e ampliação das redes sociais de suporte.

Dessa maneira, as ações da terapia ocupacional social implicam em um conhecimento e acompanhamento próximos das questões pertinentes àquela problemática social na qual se propõe a intervir, desde sua compreensão macro-estrutural, perpassada pela situação do território, pelas características da comunidade, pelo mapeamento das redes de suporte, pela intersetorialidade administrativa e política, até as histórias de vida, relações e modos de existir das pessoas e grupos em suas singularidades e subjetividades.

Ainda, a implementação de intervenções no campo social busca a criação de novas metodologias participativas, assim como a discussão sobre o papel social dos técnicos no enfrentamento de problemáticas contemporâneas.

Integrando os fundamentos dessa proposta, faz-se necessária a compreensão e o estreitamento das associações com o aparato público, representado por diferentes estruturas, instituições e relações. Indubitavelmente, nesse campo, dentre outros segmentos, a educação está presente como bem necessário e inquestionável a qualquer pessoa e sociedade, conseguindo se projetar no imaginário coletivo como um direito de todos, assim como no nosso texto

(1) O estado de vulnerabilidade social é produzido na conjunção da precariedade do trabalho com a fragilidade do vínculo social, sendo uma categoria capaz de descrever a situação de uma grande parcela da população brasileira. São diversos os fatores que confluem para a dissociação social. Extrema desigualdade, a migração para os grandes centros urbanos, precariedade de moradia, características históricas da formação da família nuclear brasileira, em um contexto de precarização do trabalho, levam, muitas vezes, a uma situação de rupturas de participação e da coesão social. Nessa concepção, é preciso desenvolver estratégias e ações que promovam os direitos e a participação advindos da cidadania de grupos sociais específicos: pessoas em situação de rua, idosos sem recursos, chefes de família monoparentais, especialmente mulheres, sem proteção, semterras, sem-teto, operários sem empregos, adolescentes e jovens pobres e outros. Para isto, é, igualmente, fundamental criar estratégias para fortalecer as redes sociais de suporte, evitando rupturas trazidas por situações nas quais a vulnerabilidade já está presente (LOPES, 2007, p.249).

(2) A noção de território adotada supõe um espaço delimitado geograficamente, construído historicamente e com relações socioeconômicas e culturais a serem conhecidas. Nele se pode observar diferentes maneiras de existir, sonhar, viver, trabalhar e realizar trocas sociais

(OLIVER; BARROS, 1999). 
constitucional, de maneira que, desde o final do século passado, ela tem alcançado proporções mais universalizantes no Brasil, especialmente no Ensino Fundamental do ciclo básico. Embora esta discussão transcenda à instituição escolar, é ela que ocupa a centralidade na representação do processo educacional, sobretudo formal, inclusive para aqueles que nunca tiveram a possibilidade de acessá-la.

A intervenção terapêutico-ocupacional sempre considerou a escola, assim como outras instituições que promovam processos sócio-educativos ${ }^{(3)}$, como equipamentos sociais relevantes que, historicamente, permitiram o acesso de grupos populares à visibilidade social, às experiências educacionais, culturais e/ou, ainda, possibilitaram melhores condições de vida.

Experiências nacionais e internacionais têm sido descritas e revelado a escola como foco da atenção da terapia ocupacional. Os objetivos que norteiam esses trabalhos visam, sobretudo, à integração e à inclusão ${ }^{(4)}$ de crianças no sistema regular de ensino, seja na sua primeira inserção escolar ou na transição da educação especial, quer dizer, a inclusão das crianças das salas especiais e/ou escolas especiais para o sistema formal. Os recursos como atividades, recreação, tecnologia assistiva, comunicação alternativa, capacitação e assessoria de profissionais da área da educação entre outros, são estratégias prioritárias da terapia ocupacional para a inclusão dos portadores de necessidades educativas especiais. Entretanto, para além das questões relacionadas à educação especial, as experiências de intervenção do Núcleo da Universidade Federal de São Carlos (UFSCar) do Projeto METUIA (BARROS et al., 2002), desde 2004, demonstram o empenho em trabalhos direcionados às questões específicas da adolescência e da juventude de grupos populares urbanos correlacionados à educação e à escola pública.

Tomando-se como referência os pressupostos da terapia ocupacional social, anteriormente citados, os problemas relacionados aos direitos e ao exercício da cidadania de adolescentes e jovens brasileiros pobres têm se constituído enquanto um campo que requer sua percepção e sua incorporação no rol das responsabilidades dos técnicos, a fim de que sejam articuladas possíveis soluções para problemas urgentes. A desigualdade, a pobreza são problemáticas relevantes no bojo da questão social brasileira, adquirindo configurações que demandam uma revisão imediata das profissões e das pertinências do papel profissional. (BARROS et al., 2007, p.351).

Em relação a definições sobre adolescência e juventude, temos, segundo a Organização Mundial de Saúde, que a adolescência constituiria um processo fundamentalmente biológico, durante o qual se acelera o desenvolvimento cognitivo e a estruturação da personalidade. Abrangeria as idades de 10 a 19 anos, divididas nas etapas de pré-adolescência (dos 10 aos 14 anos) e de adolescência propriamente dita (de 15 a 19 anos). Já o conceito "juventude" resumiria uma categoria essencialmente sociológica, que indicaria o processo de preparação para os indivíduos assumirem o papel de adulto na sociedade, tanto no plano familiar quanto no profissional, estendendo-se dos 15 aos 24 anos (OMS/ OPS, 1985). Do ponto de vista legal, no Brasil, o Estatuto da Criança e do Adolescente (ECA) estabelece a adolescência entre 12 e 18 anos $^{(5)}$.

Se considerarmos, portanto, o binômio 'educação e adolescência/juventude de grupos populares urbanos', temos um universo de contradições. Embora, historicamente, os conceitos e as designações acerca da educação e da juventude tenham sido transformados e ressignificados, a complexidade e os avanços dessas definições não impediram a constância, no Brasil, de uma certa visão de 'educação e juventude', aquela que só cabe aos adolescentes e jovens filhos da elite.

É reconhecido, ainda, que as políticas voltadas para a juventude que atendam, verdadeiramente, às demandas, numa perspectiva que efetive a noção dessa população como sujeitos de direitos, têm sido insuficientes, fragmentadas e pouco adequadas (SPOSITO; CARRANO, 2003). O que torna a escola em geral, mas, sem dúvida, especialmente, a

\footnotetext{
${ }^{(3)}$ A Terapia Ocupacional Social também têm apontado a educação não-formal como estratégia relevante de práticas educacionais propagadas para além da instituição escolar.

(4) A partir do final dos anos 1980, o termo integração começou a perder força, sendo substituído pela idéia de inclusão, uma vez que o objetivo é incluir, sem distinção, todas as crianças, independentemente de suas habilidades. A inclusão exige a transformação da escola, pois defende a inserção no ensino regular de alunos com quaisquer déficits e necessidades, cabendo às escolas se adaptarem às necessidades deles, ou seja, a inclusão acaba por exigir uma ruptura com modelos tradicionais de ensino.

(5) Todavia, não existe uma unanimidade acerca da faixa etária que melhor caracterize essas populações. Segundo Freitas (2005), para o caso de se designar o período juvenil, em determinados contextos e por usos instrumentais associados, este se amplia para baixo e para cima, podendo estender-se entre uma faixa máxima desde os 12 aos 35 anos, como se constata em algumas formulações de políticas públicas dirigidas ao setor juvenil.
} 
pública, um equipamento social ainda mais relevante.

\begin{abstract}
É importante ressaltar que promover as melhorias na educação sem uma combinação de políticas universalizantes, portanto, que seja capaz de prover educação para todos, e focalizadas naqueles que tem maior dificuldade ao acesso devido à sua classe social, não irá reduzir a desigualdade educacional e mesmo a desigualdade social. O pressuposto é de que a educação cumpra seu papel importante no quadro mais geral de um desenvolvimento sustentado e de longo prazo para o país. Desenvolvimento sustentado pressupõe necessariamente diminuição da desigualdade social, e da educacional, em particular (LOPES et al., 2006, p. 121-122).
\end{abstract}

Dessa forma, a escola, como importante espaço público, também se tornou palco de disputas e lutas de classes, entre Estado e mercado, direitos e privilégios, discurso e prática, universalização e exclusão. Este cenário corrobora o desafio da realização de reflexões sobre as singularidades e subjetividades pessoais e culturais no processo de vivência da juventude, em um contexto de absoluta desigualdade social e de não vivência de direitos e cidadania, como se constitui a sociedade brasileira.

A educação como direito é respaldada, juridicamente, por diversos documentos, inclusive aqueles de caráter internacional ${ }^{(6)}$; U UNICEF (1999) coloca que a convenção sobre os direitos da criança é clara: a educação é o fundamento de uma vida livre e desenvolvida. Todavia, o Brasil inicia o século XXI com 1,5 milhões de crianças trabalhadoras e 15 milhões de analfabetos (acima de 15 anos) e os últimos resultados do censo do professor mostram o quadro de profundas desigualdades regionais tanto em relação à qualificação quanto aos níveis de remuneração dos professores. Isto comprova a necessidade de políticas que melhorem a distribuição dos recursos e que garantam maior eqüidade na oferta do ensino público (INEP, 2000).

Por outro lado, dados demonstram que $96,9 \%$ da população entre 7 a 14 anos está na escola, o que representa a recente e efetiva democratização do acesso ao ensino fundamental. Contudo, $55 \%$ dessas crianças que cursam a $4^{\text {a. }}$ série têm competência abaixo do que é considerado apropriado na leitura. Dados recentes (INEP, 2004) indicam que $42 \%$ dos alunos do último ano do ensino médio estão nos estágios "muito crítico" e "crítico" para o desenvolvimento de habilidades e competências em 'Língua Portuguesa' e cerca de $52 \%$ dos alunos estão no estágio "intermediário". Os denominados "adequados" somam apenas $5 \%$. A verdadeira universalização do ensino inclui, portanto, além do acesso, a permanência, a progressão e a conclusão em idade adequada, obedecendo a padrões mínimos estabelecidos de qualidade.

Ao nos determos sobre esse quadro, contatamos que essa situação de risco educacional e exclusão escolar de crianças e jovens de grupos populares está presente desde sua instituição; historicamente, a própria escola é agente de uma exclusão que transforma a experiência dos alunos e abre uma crise de sentido nos estudos, às vezes, até da legitimidade da instituição escolar. A escola convida, um século após a formação da escola republicana, a nos interrogarmos sobre as finalidades da educação e, ainda, se as práticas escolares conseguem alcançar as necessidades sociais admitidas e ratificadas por nosso aparato legal. Essa ambigüidade presente na escola, tida como instrumento extremamente necessário e importante, exclui aquele que não ingressa nesse modelo ou não consegue se manter nele. Com efeito, a exclusão escolar é o resultado "normal" da extensão de uma escola democrática de massa que afirma, ao mesmo tempo, a igualdade dos indivíduos e a desigualdade de seus desempenhos.

É sempre bom ter claro que as escolas são antidemocráticas não pelos conteúdos que ensinam, mas por sua função, a de preparar diferentemente os intelectuais segundo o lugar que irão ocupar na sociedade, e, portanto, segundo sua origem de classe, como dirigentes ou como trabalhadores (GRAMSCI, 1978, p. 136).

O ensino médio, retrato dessa contradição, tem passado periodicamente por reformulações em seus conceitos e finalidades para atender às demandas políticas e econômicas. Somente na última década de 80 , teve início a democratização do acesso a esse nível de ensino. Desde então, foi o nível educacional que mais cresceu em todo o país, abrigando, contudo, a maioria absoluta dos alunos advindos de grupos populares e trabalhadores nas escolas públicas e no período noturno, o que representa maiores dificuldades, piores condições e baixo rendimento escolar, expresso em altas taxas de evasão e repetência, mantendo, assim, a distinção entre as classes (MARCÍLIO, 2005).

Um contingente representativo dos jovens brasileiros matriculados atualmente no ensino médio está em idade compatível com o ingresso no mercado de trabalho. Além disso, muitos deles pertencem a famílias pobres, dependentes da renda que o jovem pode auferir ingressando no mercado de trabalho. O resultado é que quase a metade dos alunos trabalha, e boa parte tende a estudar à noite. Acabam, então,

(6) Como o artigo XXVI da Declaração Universal dos Direitos do Homem, de 1948, a Convenção Relativa à Luta contra a Discriminação no Campo do Ensino, de 1960, os artigos 13 e 14 do Pacto Internacional dos Direitos Econômicos, Sociais e Culturais, de 1966. 
sendo afetados cumulativamente pela pobreza, pela dupla jornada, pelo turno da noite e por outros fatores (INEP/ MEC, 2004, p.20).

Em relação ao nível de escolaridade média da população de 15 anos ou mais, este é de apenas 6,7 anos (GOULART et al., 2006). Isto pode ser explicado pela baixa eficiência do sistema educacional brasileiro em produzir concluintes $^{(7)}$.

O debate sobre a escola para a juventude pobre, ou advinda das classes trabalhadoras, está presente desde início do século passado com o discurso da formação para o trabalho, evidenciando o crivo social, de classe, colocado; concebendo esse jovem como mão-de-obra a ser minimamente qualificada. As escolas técnico-profissionais foram organizadas na década de 1930 com a Reforma Francisco Campos e as Leis Orgânicas dos anos 1940 com o objetivo de atender aos grupos populares, contudo, numa visão mais assistencial que educacional, por meio do trabalho como princípio pedagógico. A regeneração pelo trabalho era o lema dessas escolas.

Para Nosella e Buffa (1998), a dualidade 'escola secundária/superior para as elites' e a 'primária/profissional para trabalhadores' persiste, apesar de muitos esforços para superá-la. A crise profunda pela qual a escola passa hoje é, também, reflexo de sua incapacidade pedagógica de formular currículos e métodos que incorporem o trabalho produtivo sem renunciar à dimensão desinteressada e universal da cultura clássica (NOSELLA; BUFFA, 2002).

Já nos anos 1990, o prolongamento da escolaridade tornou-se impositivo, sobretudo em relação ao mercado de trabalho que passou a exigir uma maior e mais sofisticada escolaridade. Nesse contexto, a Lei de Diretrizes e Bases da Educação, de 1996, reformula o ensino médio, com o objetivo de expandi-lo e melhorar sua qualidade.

O ensino médio deixou de formar exclusivamente as elites para o acesso à universidade, como foi a nossa tradição de quase cinco séculos. A democratização do ensino, a expansão da escola pública, os investimentos do Estado na expansão do atendimento ao ensino médio buscaram atender às necessidades de uma sociedade industrializada, urbanizada e com exigências de qualificação profissional (MARCÍLIO,
2005, p.434).

Apesar de ser um setor fundamental nas políticas públicas para a juventude, o ensino médio enfrenta, cotidianamente, o embate entre seus objetivos e suas reais condições de projetar a imensa maioria de adolescentes e jovens brasileiros em direção a uma vida de realizações, seja no mercado de trabalho, seja na formação para o ensino superior. Um percentual absolutamente relevante de jovens é excluído da escola no Brasil, em um processo em que vivenciam a violência dessa discriminação produzida no contexto escolar, com a não manutenção do acesso, com a falta de qualidade de ensino e, por fim, com a enorme barreira da desigualdade na construção de seus projetos de vida.

A escola pública precisa alavancar processos pedagógicos e administrativos capazes de responder aos anseios desses jovens que se incluem de forma cada vez mais presente e se confrontam com a instituição escolar quando esta não parece acolhê-lo ou integrá-lo de maneira efetiva. A gestão democrática da escola apresenta enormes desafios e tendências à exclusão, refletindo a sociedade na qual se insere.

É neste contexto repleto de contradições que a terapia ocupacional social que advogamos compreende as implicações de suas ações no campo da educação e da juventude. As experiências desenvolvidas pelo Núcleo UFSCar do Projeto METUIA, nessa perspectiva ${ }^{(8)}$, têm lidado com essas problemáticas e contribuído com propostas de intervenção que buscam solucioná-las. Chama-se a atenção para o trabalho com um grande número de adolescentes e jovens, com destaque para as "Oficinas de Atividades e Projetos", bem como com professores e com a direção escolar.

Um último ponto que queremos evidenciar refere-se ao fato de elegermos a escola pública como parceira prioritária: é nela que, ainda, encontramos o jovem pobre; daí decorre ser ela uma estratégia fundamental para a promoção e o fomento de projetos que de fato possam garantir melhores condições de vida e de experiências acerca da participação política e democrática a esses jovens. Para nós, a garantia dos direitos deve ser buscada na ampliação da esfera pública, apoiada no fortalecimento das ações e das políticas públicas com relação a setores sociais essenciais como é a educação.

\footnotetext{
(7) Pois, se por um lado o acesso é quase universal, por outro, ainda é baixo o percentual daqueles que concluem o ensino fundamental, sobretudo, na idade adequada. Haveria, portanto, uma população de quase $20 \%$ do total de matrículas no ensino fundamental que já poderia cursar o ensino médio, mas que permanece retida no nível anterior, sem que se leve em conta aqueles que evadiram (GOULART et al., 2006).

${ }^{(8)}$ Recriando Caminhos e Construindo Perspectivas: Enfretamento das Violências Urbanas entre Adolescentes e Jovens de Grupos Populares (2005-2006), Juventude, Violência e Cidadania em Grupos Populares Urbanos: intervenção coletiva e desenvolvimento social (2006-2007), Oficinas na Escola de Tempo Integral: proposições e possibilidades (2007), Construindo Cidadania: recursos audiovisuais entre jovens de grupos populares urbanos (2007), dentre outras.
} 
Os espaços públicos, segundo Hannah Arendt (1995), pautam-se pela dimensão do reconhecimento do direito, do bem público, 'publicizando' conflitos, criando arenas para seu encaminhamento. A ausência de tais espaços demonstra as dificuldades em se formular as questões sociais cotidianas na linguagem pública do direito. A cultura de uso dos espaços públicos prevê que a diferença será expressa, pois valores estarão em circulação, argumentos e opiniões em debate, como vias para se constituir uma moralidade pública estabelecida pela convivência democrática com as diferenças e conflitos. É esta possibilidade que abriria canais de comunicação social para o debate sobre as juventudes em convivência na sociedade brasileira, sobre suas demandas a serem respondidas, sancionadas ou não, pela dimensão do direito.

Como nos ensina há tempos Anísio Teixeira (1999), só existirá democracia no Brasil no dia em que se montar no país a máquina que prepara as democracias. Essa máquina é a escola pública.

LOPES, R. E.; SILVA, C. R. The field of education: possible contributions of occupational therapy in Brazil. Rev. Ter. Ocup. Univ. São Paulo, v.18, n. 3, p. 158-164, set./dez. 2007.

\begin{abstract}
This work analysis the need of social interventions based on education and on citizenship rights, and directed towards adolescents and youngsters in a situation of social vulnerability; our particular focus is the Brazilian public school. Project METUIA has worked in the construction of theoretical bases for the elaboration of therapeutical-occupational programs in the social area, as well as in its practical experimentation. Taking as a reference the experiences and studies developed by the UFSCar Nucleus of Project METUIA, with regard to the violence $i n$ and of the public school, especially the high school, we discuss the desirable contribution of occupational therapy to the whole cycle of basic education. We assume that the occupational therapy practices have an interconnection with what the corresponding professionals think, with their opinions and attitudes before the social matters presented to them; the methods that they employ are conditioned to the way they understand reality and their own responsibility before it - those aspects, in turn, have a strong influence upon the nature of the solutions that those professionals are capable to propose. Inequality and poverty are important elements in the Brazilian social context, which demand an urgent revision of professional roles in our country.
\end{abstract}

KEY WORDS: Social occupational therapy. Education. Public school. Adolescence and youth.

\title{
REFERÊNCIAS
}

ARENDT, H. A condição humana. 7a. ed. Rio de Janeiro: Forense Universitária, 1995.

BRASIL. Estatuto da criança e do adolescente. São Paulo: Cortez, 1990.

BRASIL. Constituição: República Federativa do Brasil, Brasília: Centro Gráfico, 1988.

BRASIL. Lei n 9.394, de 20 de dez. 1996. Estabelece as Diretrizes e Bases da Educação Nacional. Diário Oficial da União. Brasília, 1996.

BARROS, D. D.; LOPES, R. E.; GALHEIGO, S.M. Terapia ocupacional social: concepções e perspectivas. In: CAVALCANTI, A.; GALVÃO C. (Org.). Terapia Ocupacional - fundamentação \& prática. Rio de Janeiro: Guanabara Koogan, 2007. p. 347-353.

BARROS D. D.; LOPES, R. E.; GALHEIGO, S. M. Projeto
Metuia - terapia ocupacional no campo social. Mundo da Saúde, v. 26, n.3, p. 365-369, 2002.

CASTEL, R. As transformações da questão social. In: BELFIOREWANDERLEY, M., BÓGUS, L., YAZBEK, M. C. (Org.) Desigualdade e a questão social. São Paulo: EDUC, 1997. p. 161-190.

DONZELOT, J. A polícia das famílias. 2a. ed. Rio de Janeiro: Graal, 1986.

FREITAS, M. V. (Org.) Juventude e adolescência no Brasil: referências conceituais. São Paulo: Ação Educativa, 2005.

GALHEIGO, S. M. Repensando o lugar do social de um campo de conhecimento em terapia ocupacional. In: CONGRESSO BRASILEIRO DE TERAPIA OCUPACIONAL, 6. Águas de Lindóia, SP, 1999. Programas e resumos. Águas de Lindóia, 1999. 
LOPES, R. E.; SILVA, C. R. O campo da educação e demandas. Rev. Ter. Ocup. Univ. São Paulo, v.18, n. 3, p. 158-164, set./dez. 2007.

GOULART, O.M.T., SAMPAIO, C.E.M., NESPOTI, V. O desafio da universalização do ensino médio. Brasília: Instituto Nacional de Estudos e Pesquisas Educacionais Anísio Teixeira, 2006.

GRAMSCI, Antonio. Os intelectuais e a organização da cultura. Rio de Janeiro: Civilização Brasileira, 1978.

INEP - Instituto Nacional de Estudos e Pesquisas Educacionais Anísio Teixeira, Ministério da Educação. Resultados Finais do Censo Escolar de 2000. Disponível em: http://www.ibge.org.br

INEP - Instituto Nacional de Estudos e Pesquisas Educacionais Anísio Teixeira, Ministério da Educação. Relatório Qualidade da Educação: uma nova leitura do desempenho dos estudantes da $3^{\text {a }}$ série do ensino médio. 2004.

LOPES, R. E. Redes sociais de suporte. In: PARK, M. B.; SIERO, R. F.; CARNICEL, A. (Org). Palavras-chave em educação não-formal. Holambra: Editora Setembro; Campinas: Centro de Memória da UNICAMP, 2007. p. 249-250.

LOPES, R. E.; SILVA, C. R.; MALFITANO, A. P. S. Adolescência e Juventude de Grupos Populares Urbanos no Brasil e as Políticas Públicas: Apontamentos Históricos. Rev. HISTEDBR, Campinas [on-line], n. 23, p. 114-130, 2006.
MARCÍLIO, M.L. História da escola em São Paulo e no Brasil. São Paulo: Instituto Braudel e Imprensa Oficial, 2005.

NOSELLA, P.; BUFFA, E. Artes liberais a artes mecânicas: a difícil integração. ANPEd, 1998.

NOSELLA, P.; BUFFA, E. Schola Mater: a antiga Escola Normal de São Carlos 1911-1933. São Carlos: EdUSFCar, 2002.

OLIVER, F. C.; BARROS, D. D. Reflexionando sobre deinstitucionalización y terapia ocupacional. Matéria prima - primeira. Rev. Independiente Ter. Ocup., Argentina, v. 4, n. 13, p. 17-20, 1999.

OMS/OPS. La salud del adolescente y el joven en las Américas. Washington, D.C., 1985.

SPOSITO, M. P. e CARRANO, M. C. R. Juventude e políticas públicas no Brasil. Rev. Bras. Educ., n. 24, 2003.

TEIXEIRA, A. Educação não é privilégio. 6a. ed. Rio de Janeiro: Editora da UFRJ, 1999.

UNICEF. Relatório sobre a situação das crianças no mundo. 1999. 